\title{
Preface to CFSv2 topical collection
}

\author{
Jin Huang · Annarita Mariotti · Jim Kinter · \\ Arun Kumar
}

Published online: 11 September 2014

(C) Springer-Verlag (outside the USA) 2014

We are pleased to present the Topical Collection of the Climate Forecast System version 2 (CFSv2). The CFS is a coupled global climate model used for operational intraseasonal-to-interannual (ISI) prediction at the National Centers for Environmental Prediction (NCEP). NCEP developed CFSv2 over the course of several years and implemented it into operations in March 2011. External community research supported by the Climate Program Office (CPO) enhanced core internal development and evaluation. To bring the broader climate research and applications community together with NCEP scientists to evaluate the utility of CFSv2 for climate modeling research and as a climate forecast tool, the NCEP Climate Prediction Center (CPC), NOAA Climate Test Bed (CTB), Center for

This paper is a contribution to the Topical Collection on Climate Forecast System Version 2 (CFSv2). CFSv2 is a coupled global climate model and was implemented by National Centers for Environmental Prediction (NCEP) in seasonal forecasting operations in March 2011. This Topical Collection is coordinated by Jin Huang, Annarita Mariott, Jim Kinter, and Arun Kumar.

\section{J. Huang $(\square)$}

NCEP Climate Test Bed, 5830 University Research Court,

College Park, MD 20740, USA

e-mail: Jin.Huang@noaa.gov

\section{A. Mariotti}

NOAA Climate Program Office, 1315 East/West Hwy,

Silver Spring, MD 20910, USA

J. Kinter

Department of Atmospheric, Oceanic and Earth Sciences, Center for Ocean-Land-Atmosphere Studies, George Mason University, 4400 University Drive, Fairfax, VA 22030, USA

\section{A. Kumar}

NCEP Climate Prediction Center, 5830 University

Research Court, College Park, MD 20740, USA
Ocean-Land-Atmosphere Studies (COLA), and NOAA CPO organized a CFSv2 Evaluation Workshop in 2012. This topical collection includes a selection of peer-reviewed papers consisting of material presented at the workshop.

The more than 20 papers in this collection have documented significant progress in the performance of CFSv2 in simulating ISI climate variability and predicting key climate variables, in comparison to the previous NCEP operational climate forecast system. The papers have also identified key model biases and deficiencies in predicting climate variables (such as precipitation and temperature), simulating the modes of climate variability and phenomena (such as El Niño and the Southern Oscillation or ENSO, the MaddenJulian Oscillation or MJO, the Arctic Oscillation or AO, global and regional drought, and monsoons) and physical processes and their interactions (such as cloud distributions, land-atmosphere interactions, and ocean-atmosphere interactions). This collection of papers is expected to provide insight into and guidance for the development of the next generation operational CFS. We'd like to express our sincere appreciation to Professor Edwin Schneider for his effort and dedication as the Chief Editor for this special collection. 